\title{
Two cases of gallbladder metastasis from renal cell carcinoma and review of literature
}

\author{
Mafalda Costa Neves ${ }^{1,2^{*}}$, Kyriakos Neofytou', Alexandros Giakoustidis ${ }^{2}$, Stephen Hazell ${ }^{3}$, Andrew Wotherspoon ${ }^{3}$, \\ Martin Gore ${ }^{4}$ and Satvinder Mudan $1,2,5$
}

\begin{abstract}
Background: Renal cell carcinoma accounts for $90 \%$ of renal neoplasms and metastatic disease is common. One third of newly diagnosed cases will have synchronous metastases at diagnosis and further 25-50\% will develop metachronous disease.

Case Presentation: This study presents two new cases of gallbladder metastasis from renal cell carcinoma (RCC) from our institution and reviews the published literature. The final cohort included 52 evaluable patients. M/F ratio was 2:1 and median age was 62.5 years. Most patients were diagnosed incidentally after follow-up or staging imaging for RCC. Of the patients with available histology, all except one were clear cell type $(n=39)$ and $92 \%$ were polypoid. Thirty-six patients demonstrated metachronous gallbladder metastasis with median disease-free interval (DFI) from nephrectomy of 4 years. The most frequent site of metastasis was the contralateral kidney (46.7 \%) followed by the pancreas and lung. The median disease-free interval (DFS) after cholecystectomy was 37 months. Three- and five-year OS rates were 74 and $62 \%$, respectively. Age younger than 45 years $(p=0.008)$ and DFI $<24$ months $(p=0.049)$ were associated with decreased OS.

Conclusions: RCC metastasis to the gallbladder is associated with an unusual pattern of concomitant metastasis. Symptoms are not common. Simple cholecystectomy is associated with increased OS and nil local or port site recurrence. Young age and short DFI are associated with decreased OS.
\end{abstract}

Keywords: Cancer, Gallbladder, Kidney neoplasms, Clear cell metastatic renal cell carcinoma

\section{Background}

Renal cell carcinoma accounts for approximately $3 \%$ of malignancies in adults and $90 \%$ of renal neoplasms [1]. Metastatic disease is common, and one third of newly diagnosed cases will have synchronous metastatic disease at presentation. A further $25-50 \%$ will develop metachronous disease [2]. Latent distant metastasis is characteristic of renal cell carcinoma (RCC) and can manifest more than a decade after nephrectomy in about $10 \%$ of patients [3].

\footnotetext{
* Correspondence: mafaldajardim@hotmail.com

'Academic Surgery Department, The Royal Marsden NHS Foundation Trust, Fulham Road, London SW3 6JJ, UK

${ }^{2}$ Surgery Department, The London Clinic, 116 Harley Street, London W1G 7JL, UK

Full list of author information is available at the end of the article
}

Clear Cell (CC) RCC is the most common type of renal cancer, accounting for $75 \%$ of all primary kidney tumours. Similar to other malignancies, RCC may undergo differentiation to more aggressive histological types. Sarcomatoid transformation is present in $5 \%$ of RCC, although these do not in themselves represent a distinct histological entity [4]. Spindle cell morphology, similar to sarcomas, can occur in all types of RCC but is most often seen in clear cell and chromophobe RCC [5]. These patients have an adverse stage stratified prognosis with a median survival of 4-19 months [6].

The most common sites of metastasis of RCC are the lung, bone, liver, adrenal gland, brain and contralateral kidney but have been documented in nearly every organ. Gallbladder involvement is reported in $<1 \%$ of cases. The outcome for metastatic RCC is poor, bearing a 
5-year survival rate of approximately 5-10 \%, but curative resection of metastasis in selected patients is known to improve long-term survival $[4,7]$.

\section{Materials and methods}

The review of literature was based on a systematic PubMed search to identify all published cases of RCC metastasis to the gallbladder and including cases described in the Japanese literature. The final analysis included 52 patients, 2 from our institution and 50 from previous published cases (Table 1, database available in Additional file 1: Table S1). Four articles were excluded because of unavailability of content or omission of basic information particularly sex, age and interval between nephrectomy and the diagnosis of metachronous gallbladder lesion. When available, the data was collected to focus on demographics, histology and staging of the primary tumour, disease-free interval (DFI) from nephrectomy, size and extent of invasion into the gallbladder, presence of gallstones, disease-free survival, adjuvant therapy, follow-up time, and outcome.

The two case reports presented resulted from a 5-year retrospective search through The Royal Marsden Hospital's histopathological archives from gallbladder specimens. Data was collected through review of patient history, operative notes, pathology reports, and medical records after consent.

\section{Statistical analysis}

Statistical analysis was performed with the Statistical Package of the Social Sciences (SPSS), version 17.0. The primary endpoints of the study were DFI between resection of primary renal tumour and presentation of metachronous gallbladder metastasis. Overall survival (OS) was calculated from the date of operation for the gallbladder metastasis to the date of disease-related death and was censored at the time of last follow-up for patients that were alive or at the time of death when unrelated to the disease. The impact of clinicopathological characteristics on OS was analysed using both the KaplanMeier and univariate Cox regression methods. Survival outcomes between groups were compared with the log-rank test.

A chi-square test, Mann-Whitney non-parametric test and Fischer's exact test were used when appropriate for calculating the association between clinicopathological characteristics and interval between resection of primary renal tumour and presentation of metachronous gallbladder metastasis, recurrence or disease-related death. A $p$ value of less than 0.05 was considered statistically significant.

\section{Case 1}

In February 2012, a 60-year-old female presented with a urinary tract infection (UTI), right loin pain and haematuria. In spite of effective treatment of the UTI, the loin pain persisted. Evaluation by biphasic enhanced CT confirmed the presence of a 4-cm hypo-attenuating mass occupying the lower pole of the right kidney without invasion of the major renal vein or cava and without lymph node enlargement. A number of nodules highly suggestive of metastasis were present in both lungs, the largest measuring $6.5 \mathrm{~mm}$. CA 19.9, CA 15.5 and CEA were negative. The patient underwent an uneventful laparoscopic right radical nephrectomy. Histology of the specimen showed CC RCC Leibovich score 1, pT1aN0 and Fuhrman grade 3.

Follow-up CT scan after 2 months showed no recurrence and stability of the lung lesions, but the scan at month 5 showed total regression of the pulmonary nodules. Follow-up CTs every 6 months were unremarkable until July 2014, when a gallbladder mass was revealed. She had a further MRI, which showed a $2.5-\mathrm{cm}$ intraluminal polypoid mass in the inferior wall of the gallbladder. A laparoscopic cholecystectomy was performed and the patient was discharged the following day. Histopathology reported a $30 \times 20 \mathrm{~mm}$ polypoid submucosal metastatic deposit of CC RCC with an extensively ulcerated surface, composed of large nests and sheets of moderately sized polygonal cells with delicate cell borders and clear cytoplasm and central nucleus showing hyperchromasia without a prominent nucleolus (Fig. 1). The polyp was confined to the gallbladder with no extension into serosa. Immunohistochemistry showed the tumour cells to strongly express PAX8, Vimentin, CAM5.2, AMACR and EMA, focal E-cadherin expression with no tumour expression of CD10, RCCAg, CK7, or CD117.

The patient did not receive adjuvant therapy and remained disease-free after 2 months of follow-up.

\section{Case 2}

A 57-year-old male with a previous history of resected melanoma from the right arm (T1a) presented with sudden onset of acute abdominal pain and macroscopic haematuria in May 2011. A CT scan showed a $12 \times 10 \times$ $8 \mathrm{~cm}$ mass in the left kidney extending into the hilum consistent with RCC and a gallbladder polyp. A number of bilateral small peripheral and sub-pleural pulmonary nodules measuring less than $5 \mathrm{~mm}$ and of indeterminate nature were present. In June 2011, the patient underwent an open radical nephrectomy and adrenalectomy, with an uneventful recovery. Pathology revealed a CC RCC Fuhrman 4 with extensive sarcomatoid changes and areas of necrosis, invading muscular veins of renal sinus including the main renal vein but without invasion 
Table 1 Review of literature

\begin{tabular}{|c|c|c|}
\hline Authors & No. of cases & Source \\
\hline Jain & 1 & Saudi J Kidney Dis Transpl 2013 Jan;24(1):100-4 \\
\hline Zygulska & 1 & Pol PrzegIChir 2012 Jun;84(6):313-6 \\
\hline Robledo & 1 & OncolLett 2012 May;3(5):1136-1138 \\
\hline Zevallos Quiroz & 1 & Cir Esp 2014 Apr;92(4):295-6 \\
\hline Decoene & 1 & Case Rep Med 2011;2011:671645 \\
\hline Chung & 4 & UrolOncol 2012 Jul-Aug;30(4):476-81 \\
\hline Kawahara & 1 & Case Rep Oncol 2010 Jan 29;3(1):30-34 \\
\hline Fang. & 4 & Arch Pathol Lab Med 2010 Jul;134(7):1003-9 \\
\hline Shoji & 1 & OncolLett 2010 May;1(3):507-509 \\
\hline Patel & 1 & Cases J. 2009 Oct 29;2:172 \\
\hline Kücükakin & 1 & UgeskrLaeger 2009 Aug 24;171(35):2486-7 \\
\hline Sand & 1 & Eur J Med Res 2009;14:90-2 \\
\hline Moujahid & 1 & GastroenterolClinBiol 2008 Aug-Sep;32(8-9):788-9 \\
\hline Nojima & 1 & J HepatobiliaryPancreatSurg 2008;15(2):209-12 \\
\hline Hellenthal & 1 & IntUrolNephrol 2007;39(2):377-9 \\
\hline Pandey & 1 & Indian J Gastroenterol 2006 May-Jun;25(3):161-2 \\
\hline Ishizawa & 1 & Asian J Surg2006 Jul;29(3):145-8 \\
\hline Miyagi & 1 & RinshoHinyokika 2003;57:257 \\
\hline Limani & 1 & ActaChirBelg 2003 Apr;103(2):233-4 \\
\hline Park & 1 & Yonsei Med J 2003 Apr 30;44(2):355-8 \\
\hline Gekiya & 1 & Jpn J UrolSurg2002;15:67 \\
\hline Aoki & 2 & Surg Today 2002;32(1):89-92 \\
\hline Ueki & 1 & Shoukakigazou 2001;3:373 \\
\hline Kechrid & 1 & Saudi J Kidney Dis Transpl 2000 Oct-Dec;11(4):587-92 \\
\hline Brasseur & 1 & J Radiol 1999 Jul;80(7):739-40 \\
\hline Celebi & 1 & Int J Urol 1998 May;5(3):288-90 \\
\hline Sparwasser & 1 & Urollnt 1997;58(4):257-8 \\
\hline Uchiyama & 1 & Jpn J Gastroenterol 1997;94:68 \\
\hline Furukawa & 1 & AJR 1997;169:1466 \\
\hline Kakimoto & 1 & HinyoukiGeka 1996;9:875 \\
\hline Lombardo & 1 & J Ultrasound Med 1996 Oct;15(10):725-8 \\
\hline Fujii & 1 & RinshoHinyokika 1995;49:405 \\
\hline King & 1 & Urology 1995 Nov;46(5):722-5 \\
\hline Pagano & 1 & Urology 1995 May;45(5):867-9 \\
\hline Coşkun & 1 & ActaChirBelg 1995;95:56 \\
\hline Naggler & 1 & Dig Dis Sci 1994 Nov;39(11):2476-9 \\
\hline Fullarton & 1 & Urology 1991 Aug;38(2):184-6 \\
\hline Golbey & 1 & Clin Imaging 1991 Oct-Dec;15(4):293-5 \\
\hline Satoh & 1 & Dig Dis Sci 1991 Apr;36(4):520-3 \\
\hline Terashima & 1 & Jpn J GastroenterolSurg 1990;23:1952 \\
\hline Harder & 1 & UgeskrLaeger 1983 Oct 17;145(42):3261 \\
\hline
\end{tabular}


Table 1 Review of literature (Continued)

\begin{tabular}{lll}
\hline Oikawa & 1 & GekaShinryo 1978;20:617 \\
Botting & 1 & Mayo ClinProc 1963;38:225 \\
Costa Neves & 2 & Current cases \\
Total & 52 & \\
\hline
\end{tabular}

of perinephric fat. All nodes were negative for malignancy, staging the tumour as pT3bN0.

The next month, the patient experienced two episodes of severe upper abdominal pain, nausea and vomiting which completely subsided after administration of intravenous morphine, accompanied by unremarkable CT emergency scans. He had a Barium swallow test and an upper gastrointestinal endoscopy, both of which were normal. On the third episode of acute abdominal pain in July, he finally underwent a laparoscopic cholecystectomy with relief of symptoms. Histopathology revealed a $22 \times 15 \times 8 \mathrm{~mm}$ polyp with normal mucosa composed of nested/alveolar pattern of moderate-sized polygonal cells with clear cytoplasm and well-defined cytoplasm borders, round central nuclei with a moderate degree of nucleolar prominence, occasionally multinucleated, with fine fibro-vascular septae present within thin wall vessels and an admixture of inflammation and foamy macrophages at the periphery of the polyp. Immunohistochemistry showed these cells to express AE1/AE3, Vimentin, CD10 and RCCAg with no expression of S100 or CEA, consistent with the diagnosis of metastatic CC RCC.

The patient was followed up in an outpatient clinic accompanied by CTs at 3, 6 and 12 months post-op and annually thereafter. The bilateral lung lesions remained stable without adjuvant treatment, and the patient remained disease-free until date (total follow-up of 38 months).

\section{Results of literature review}

Patient's relevant primary tumour and gallbladder metastasis characteristics are shown in Table 2. There was a predominance of male patients $(67.3 \%)$, and the median age at presentation of gallbladder metastasis was 62.5 years old (range 39-84). Of the 34 cases with initial staging available, 19 demonstrated stage 4 disease (55.9 \%): 9 due to a single synchronous gallbladder metastasis, 7 with other synchronous metastasis and 3 with metachronous gallbladder involvement.

In most of the cases, the diagnosis was made incidentally during a radiographic exam for staging or on follow-up (74.4 \%, $n=39)$. When symptomatic, the majority of cases presented with acute or chronic biliary symptoms. Of the cases with available pathology of the gallbladder RCC metastasis, all except one were confirmed to be $\mathrm{CC} \mathrm{RCC}$, the remaining being classified as RCC "type not specified". The gallbladder lesion was persistently polypoid/pedunculated and intraluminal in $92 \%$ of cases. The mean size was $25 \mathrm{~mm}$ (range 8-75). Mucosal invasion was evident in $65 \%$, and gallstones were present in only $15.6 \%(7 / 45)$.

The majority of patients (36/52-69.2 \%) demonstrated metachronous gallbladder metastasis with a median DFI of 4 years (range $0.25-27$ ). DFI was not predicted by sex, staging, incidental diagnosis vs. symptomatic disease, single vs. multiple metastases, macroscopic appearance of gallbladder tumour, its extent of invasion in the gallbladder wall or presence of gallstones.

The gallbladder was the sole site of metastatic disease in 30/52 patients, and in $70 \%$ of these patients presented as a metachronous lesion. Patients with multiple sites of metastasis had the following pattern of disease: contralateral kidney (46.7\%), pancreas (26.7\%), lung
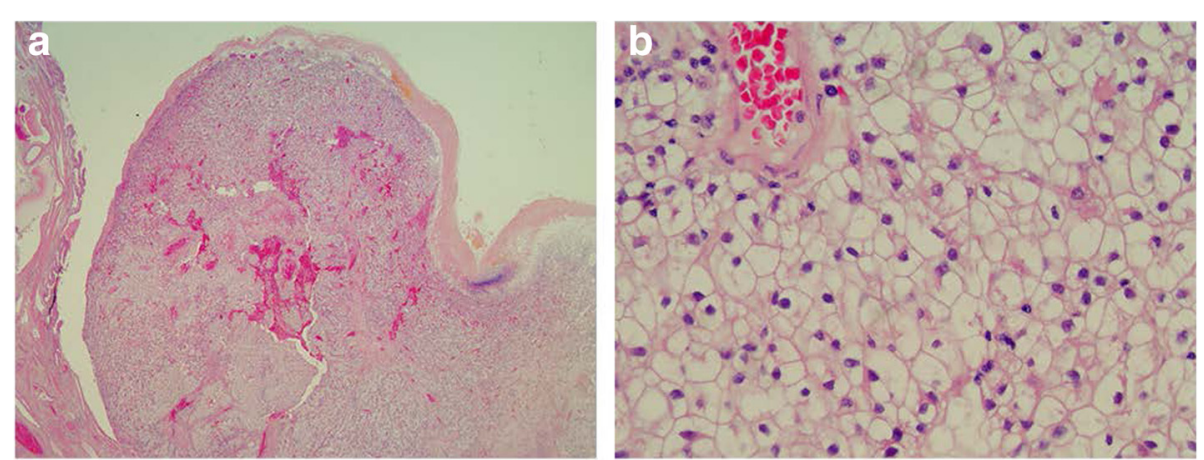

Fig. 1 Gallbladder specimen in low (a) and high-power field (b) showing the polyp confined to the gallbladder and composed of large nests and sheets of moderately sized polygonal cells with delicate cell borders and clear cytoplasm 
Table 2 Patient, primary tumour and gallbladder metastasis characteristics

\begin{tabular}{|c|c|c|}
\hline Parameter & No. of patients (\%) or median (range) & No. of patients available for analysis \\
\hline Median age (years) & $62.5(39-84)$ & $52 / 52$ \\
\hline Sex & & $52 / 52$ \\
\hline Male & $35(67.3)$ & \\
\hline Female & $17(32.7)$ & \\
\hline Stage of RCC at presentation & & $34 / 52$ \\
\hline 1 & $5(14.7)$ & \\
\hline 2 & $4(11.8)$ & \\
\hline 3 & $6(17.6)$ & \\
\hline 4 & $19(55.9)$ & \\
\hline Timing & & $52 / 52$ \\
\hline Synchronous & $16(30.8)$ & \\
\hline Gallbladder only & $9(17.3)$ & \\
\hline Gallbladder with other metastasis & $7(13.5)$ & \\
\hline Metachronous & $36(69.2)$ & \\
\hline Gallbladder only & $21(40.4)$ & \\
\hline Gallbladder with other metastasis & $14(26.9)$ & \\
\hline Unknown & $1(1.9)$ & \\
\hline DFI, years & $4(0.25-27)$ & $35 / 35$ \\
\hline Presentation & & $39 / 52$ \\
\hline Symptomatic & $10(25.6)$ & \\
\hline Radiographic & $29(74.4)$ & \\
\hline Median size of gallbladder tumour, $\mathrm{cm}$ & $25(8-75)$ & $44 / 52$ \\
\hline Extent of invasion of gallbladder & & $20 / 52$ \\
\hline Mucosa & $13(65)$ & \\
\hline Muscularis mucosa & $4(20)$ & \\
\hline Subserosa & $3(15)$ & \\
\hline Marcoscopic appearance & & $50 / 52$ \\
\hline Polypoid/pedunculated & $46(92)$ & \\
\hline Mass/nodule & $4(8)$ & \\
\hline Presence of gallstones & & $45 / 52$ \\
\hline No & $38(84.4)$ & \\
\hline Yes & $7(15.6)$ & \\
\hline Pathology & & $39 / 52$ \\
\hline Clear cell RCC & $38(97.4)$ & \\
\hline RCC type not specified & $1(2.6)$ & \\
\hline
\end{tabular}

Patients with synchronous and metachronous gallbladder metastases are highlighted in italic

(26.7\%), adrenal (20\%), skin (4.8\%), bones (4.8\%), IVC (4.8\%), ovaries (4.8\%), bladder (4.8\%) and muscle (4.8\%) (Table 3).

All patients had cholecystectomy and seven received adjuvant therapy.

At a mean follow-up of 1.6 years (range $0.1-11$ ) after cholecystectomy, $52.6 \%$ of the patients were alive with no evidence of disease, $21.1 \%$ were alive with disease,
$21.1 \%$ died from metastatic disease and $5.3 \%$ died from unrelated causes (Table 4). The median disease-free interval (DFS) was 37 months (95\% confidence interval 24-48). Three- and five-year OS rates were 74 and $62 \%$, respectively (Fig. 2). No patients developed local or port site recurrence after simple cholecystectomy.

Univariate analysis (Table 5) revealed that age less than 45 years (hazards ratio (HR) 8.98; $95 \% \mathrm{CI}, 1.78-45.18$; 
Table 3 Presentation of all sites of metastasis

\begin{tabular}{lll}
\hline Parameters & No. of patients (\%) or median (range) & No. of patients available for analysis \\
\hline Metastatic disease presentation & & $51 / 52$ \\
Metastasis to only gallbladder & $30(58.5)$ & $15 / 21$ \\
Metastasis to other sites & $21(41.2)$ & $7(46.7)^{\mathrm{a}}$ \\
Sites of other metastases & $4(26.7)^{\mathrm{a}}$ & \\
Contralateral kidney (\%) & $4(26.7)^{\mathrm{a}}$ \\
Pancreas (\%) & $3(20)^{\mathrm{a}}$ \\
Lung (\%) & $1(4.8)^{\mathrm{a}}$ \\
Adrenal (\%) & $1(4.8)^{\mathrm{a}}$ \\
Skin (\%) & $1(4.8)^{\mathrm{a}}$ \\
Bones (\%) & $1(4.8)^{\mathrm{a}}$ \\
IVC (\%) & $1(4.8)^{\mathrm{a}}$ \\
Ovaries (\%) & $1(4.8)^{\mathrm{a}}$ \\
Bladder (\%) & \\
Muscle (\%) &
\end{tabular}

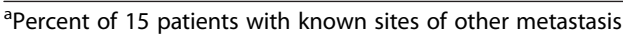

$p=0.008$ ) and DFI <24 months (HR 10.25; $95 \% \mathrm{CI}$, $1.01-103.67 ; p=0.049)$ were associated with decreased OS (Figs. 3 and 4).

\section{Discussion}

Despite the great tendency of RCC to metastasize synchronously or metachronously to numerous anatomical sites, metastasis to the gallbladder is rare. Our review of literature found 54 cases published by 43 papers dated since 1963 . Fifty cases were considered evaluable for this report and with the addition of our two cases provided a total cohort of 52 evaluable cases, thus representing the most extensive and complete database on this subject to date.

Unlike primary gallbladder cancer, RCC metastases to the gallbladder show a clear male predominance and a low incidence of concomitant gallstone disease [8, 9]. Moreover, the majority has a polypoid or pedunculated morphology (46/50) whereas primary gallbladder cancer has a diffuse wall thickening morphology [9].

The median DFI was 4 years, which is consistent with the results found by Chung et al. in their review in 2012 [10]. We found a statistically significant decrease in OS for patients younger than 45 years old and when the DFI was less than 24 months.

The clear cell type was responsible for practically all cases of metastasis of RCC to the gallbladder. It is still not clear if this is due to the fact that $\mathrm{CC}$ RCC is the most frequent type of RCC or whether this type of metastasis is exclusive to clear cell type. A sarcomatoid component generally implies a more aggressive behaviour and bears a median survival of

Table 4 Intervention, follow-up and outcome

\begin{tabular}{lll}
\hline Parameters & No. of patients (\%) & No. of patients available for analysis \\
\hline Intervention & & $51 / 52$ \\
Cholecystectomy & $51(100)$ & $27 / 52$ \\
Adjuvant therapy & $7(25.9)$ & $37 / 52$ \\
Median follow-up time, years, median (range) & $1.6(0.1-11)$ & $37 / 52$ \\
5-year OS, \% & 62 & $26 / 52$ \\
Median DFS, months (95\% Cl) & $37(24-48)$ & $38 / 52$ \\
Available outcome & & \\
No evidence of disease & $20(52.6)$ & \\
Alive with metastasis & $8(21.1)$ & \\
Death from metastasis & $8(21.1)$ & $2(5.3)$ \\
Non-cancerous death &
\end{tabular}

Abbreviations: OS overall survival, DFS disease-free survival, $\mathrm{Cl}$ confidence interval 


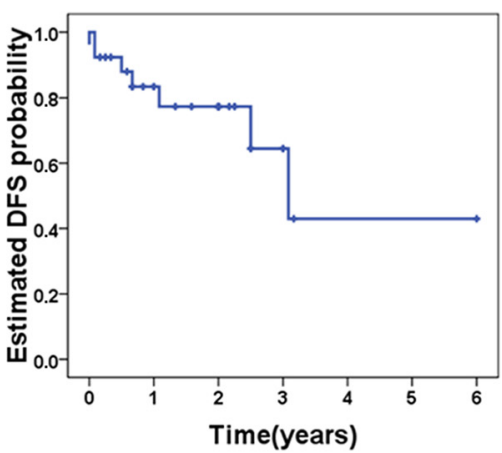

$\begin{array}{lllllll}\text { Number at Risk } & 26 & 15 & 11 & 4 & 1 & 1\end{array}$

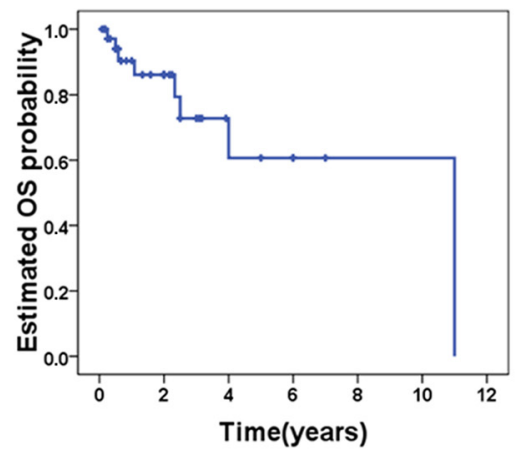

$\begin{array}{llllll}37 & 18 & 6 & 4 & 1 & 1\end{array}$

Fig. 2 Kaplan-Meier curve of disease-free survival (DFS) and overall survival (OS)

Table 5 Baseline clinicopathologic characteristics and their association with OS in univariate analysis

\begin{tabular}{|c|c|c|c|c|}
\hline Parameters & No. of patients (\%) & $\mathrm{HR}(95 \% \mathrm{Cl})$ & $p$ value & No. of patients available for analysis \\
\hline Sex & & & & $37 / 52$ \\
\hline Male & $25(67.6)$ & 1 (referent) & & \\
\hline Female & $12(32.4)$ & $1.37(0.30-6.25)$ & 0.682 & \\
\hline Age & & & & $37 / 52$ \\
\hline$>45$ & $33(89.2)$ & 1 (referent) & & \\
\hline$<45$ & $4(10.8)$ & $8.98(1.78-45.18)$ & 0.008 & \\
\hline Presentation & & & & $28 / 42$ \\
\hline Asymptomatic & $7(25)$ & 1 (referent) & & \\
\hline Symptomatic & $21(75)$ & $2.97(0.59-14.77)$ & 0.183 & \\
\hline Timing & & & & $37 / 52$ \\
\hline Synchronous ${ }^{a}$ & $14(37.8)$ & 1 (referent) & & \\
\hline Metachronous & $23(62.2)$ & $3.25(0.39-27.10)$ & 0.276 & \\
\hline Staging & & & & $28 / 52$ \\
\hline 1 & $2(7.1)$ & b & & \\
\hline 2 & $4(14.3)$ & 1 (referent) & & \\
\hline 3 & $5(17.9)$ & $0.56(0.05-6.33)$ & & \\
\hline 4 & $17(60.7)$ & $0.74(0.30-1.83)$ & 0.676 & \\
\hline Single vs. multiple & & & & $36 / 52$ \\
\hline Single & $20(55.6)$ & 1 (referent) & & \\
\hline Multiple & $16(44.4)$ & $2.77(0.50-15.28)$ & 0.241 & \\
\hline \multicolumn{3}{|c|}{ Interval from resection of primary to diagnosis of metastasis } & & $23 / 35^{c}$ \\
\hline$>24$ months & $17(73.9)$ & 1 (referent) & & \\
\hline$<24$ months & $6(26.1)$ & $10.80(1.07-108.34)$ & 0.043 & \\
\hline \multicolumn{5}{|c|}{ Adjuvant chemotherapy } \\
\hline Yes & $6(28.6)$ & 1 (referent) & & $21 / 52$ \\
\hline No & $15(71.4)$ & $2.28(0.25-20.58)$ & 0.461 & \\
\hline
\end{tabular}

Abbreviations: $H R$ hazards ratio, $\mathrm{Cl}$ confidence interval

${ }^{\mathrm{a} D}$ Diagnosis at the time of diagnosis of primary tumour

${ }^{\mathrm{b}}$ All cases are censored

'Only

Statistically significant $p$ value is highlighted in italic 


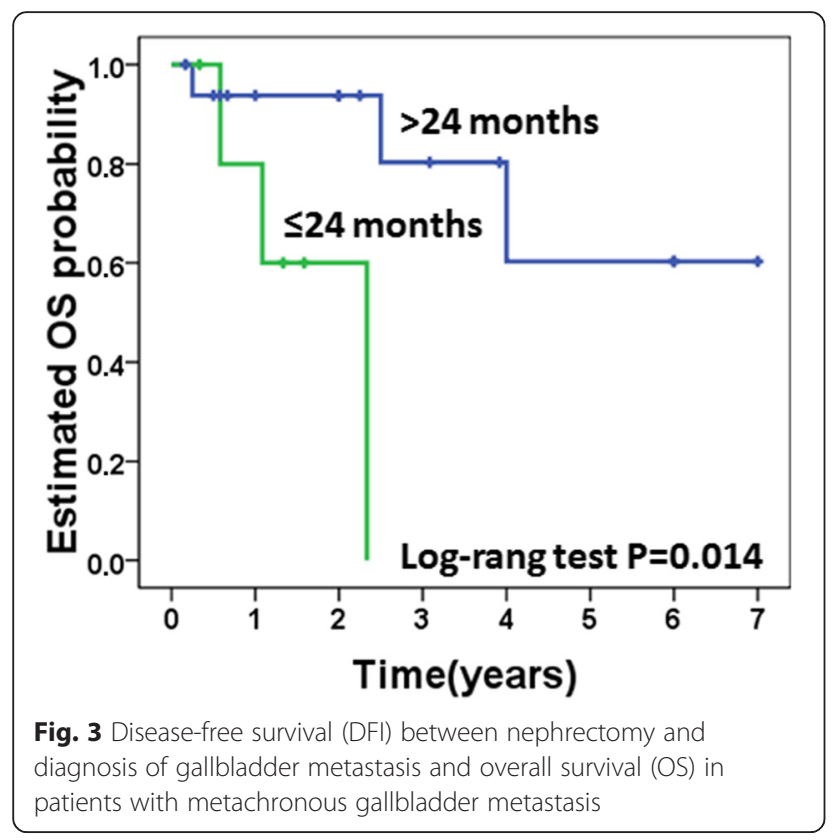

4-19 months after diagnosis [6], but our second case patient had no recurrence throughout a follow-up period of 38 months despite sarcomatoid histology.

The diagnosis of gallbladder lesion was predominantly radiographic at initial staging or at follow-up after nephrectomy. The management of gallbladder polyps remains controversial, but a review of literature published in 2012 stated that gallbladder polyps $>10 \mathrm{~mm}$, symptomatic, fast growing, sessile or wide-based; polyps with long pedicles; any size of polyp in patients $>50$ years of age; concurrent gallstones; polyps in the setting of primary sclerosing cholangitis; or abnormal gallbladder

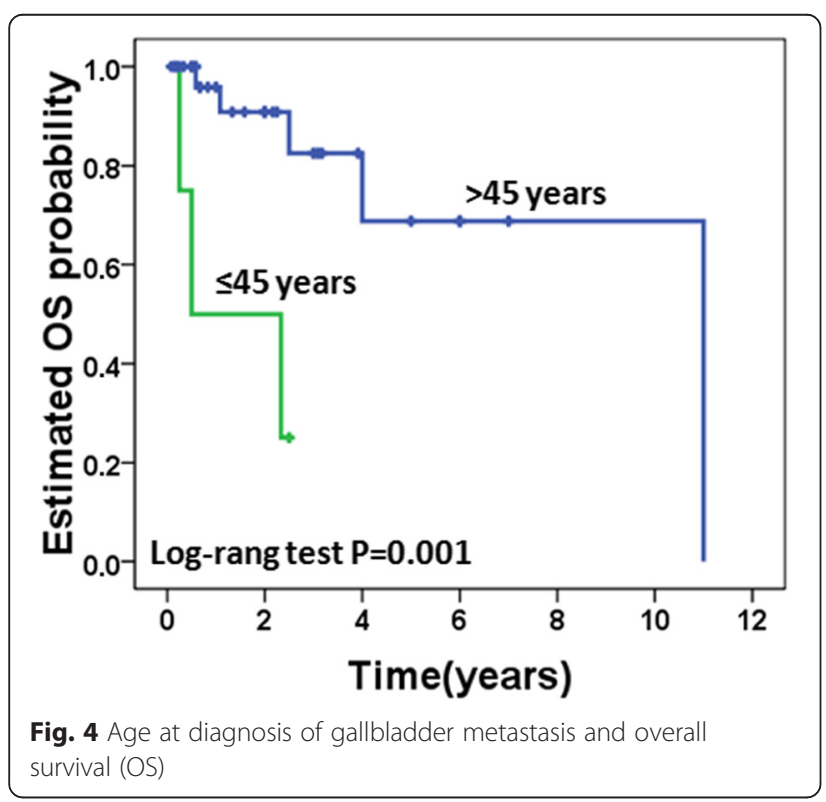

ultrasound are considered indications for surgery [11]. In the context of patients with a history of RCC, the suspicion of a metastasis should be considered.

A simple cholecystectomy is recommended for pedunculated tumours because gallbladder cancers of pedunculated type often remain within the mucosa, regardless of the tumour size [12]. In our review, no patients with RCC who underwent a simple cholecystectomy for a metastatic polypoid lesion developed local recurrence suggesting that a simple cholecystectomy is adequate when a metastasis of RCC is suspected. Laparoscopic cholecystectomy followed by a frozen section is appropriate when there is no evidence of serosal involvement at laparoscopy [11], as port site metastases from gallbladder cancer have been reported [13].

It is interesting to notice that the presence of concomitant metastasis is different when there is gallbladder involvement. In our cohort, involvement of the contralateral kidney was the most frequent site of concomitant disease, exhibiting a frequency of $46.7 \%$, contrasting with the reported $5 \%$ when gallbladder involvement is absent [14]. Pancreatic and lung involvement showed a frequency of $26.7 \%$ each. This is intriguing, as the lung is usually the most frequent site of RCC metastasis, occurring in up to $60 \%$ of patients [15], and pancreatic involvement is reported in only $2 \%$ of cases [16].

In our first case report, small bilateral lung lesions were identified and the CT suggested these to be metastatic disease. However, these lesions regressed completely 5 months after nephrectomy without adjuvant treatment. The nature of these lesions remains uncertain, because there was no tissue pathology confirmation of metastatic disease. The initial stability of the lesions and posterior total regression point towards a more probable inflammatory nature, in spite of the absence of respiratory symptoms, but spontaneous regression of lung metastasis from RCC after nephrectomy is reported $[17,18]$. In our second case report, the patient also demonstrated bilateral small lung lesions, some of them described as inflammatory on CT. These lesions never regressed but also did not progress throughout a 38month follow-up, suggesting the diagnosis of lung metastasis as unlikely.

Several phase 3 randomized controlled studies are currently in place for adjuvant treatment with sunitinib, sorafenib, pazopanib, axitinib and everolimus. As the results from these trials have not been published yet, there is still no current evidence to support adjuvant treatment after nephrectomy for RCC $[1,4]$.

\section{Conclusions}

Gallbladder metastasis from RCC is an uncommon event. Most cases are asymptomatic, hence the importance of radiological follow-up after nephrectomy. All 
gallbladder polypoid lesions in patients with a history of RCC mandate treatment, and simple cholecystectomy is associated with increased OS and nil local or port site recurrence published to date. The presence of gallbladder metastasis indicates an alteration in the pattern of subsequent disease with relapse in the contralateral kidney being the most common site of recurrence. Young age and short DFI are associated with decreased OS.

\section{Consent}

Written informed consent was obtained from the patients for publication of these case reports and any accompanying images. Copies of the written consent are available for review by the Editor-in-Chief of this journal.

\section{Additional file}

Additional file 1: Table S1. Literature review. (DOCX 34 kb)

\section{Competing interests}

The authors declare that they have no competing interests.

\section{Authors' contributions}

MCN provided the conception and design of the study and acquisition of data, drafted the article, revised it critically for important intellectual content, and gave final approval of the version to be submitted. KN was responsible for the analysis and interpretation of data and drafting of manuscript. AG participated in the conception and design of the study and reviewed the manuscript. SH studied the pathology specimens for both cases and reviewed the manuscript. AW supervised the pathology results, provided microscopy images of the specimens, screened the hospital's database for similar pathology cases, provided with important intellectual content and reviewed the manuscript. MG provided with important intellectual content and reviewed the manuscript. SM revised the article critically for important intellectual content and gave final approval of the version to be submitted. All authors read and approved the final manuscript.

\section{Acknowledgements}

None. No funding to declare.

\section{Author details}

${ }^{1}$ Academic Surgery Department, The Royal Marsden NHS Foundation Trust, Fulham Road, London SW3 6JJ, UK. ${ }^{2}$ Surgery Department, The London Clinic, 116 Harley Street, London W1G 7JL, UK. ${ }^{3}$ Pathology Department, The Royal Marsden NHS Foundation Trust, Fulham Road, London SW3 6JJ, UK. ${ }^{4}$ Urology Department, The Royal Marsden NHS Foundation Trust, Fulham Road, London SW3 6JJ, UK. ${ }^{5}$ Department of Surgery and Cancer-Faculty of Medicine, Imperial College London, London W2 1PG, UK.

Received: 26 June 2015 Accepted: 10 March 2016

Published online: 22 March 2016

\section{References}

1. Ljungberg B, Bensalah $\mathrm{K}$, Canfield $\mathrm{S}$, et al. EAU guidelines on renal cell carcinoma: 2014 update. Eur Urol. 2015;67(5):913-24. doi:10.1016/j.eururo. 2015.01.005.

2. Sand M, Bechara FG, Kopp J, et al. Gallbladder metastasis from renal cell carcinoma mimicking acute cholecystitis. Eur J Med Res. 2009;14:90-2.

3. McNichols DW, Segura JW, De Weerd JH. Renal cell carcinoma: long term survival and late recurrence. J Urol. 1981;126(1):17-23.

4. Bellmunt J, Puente J, Garcia De Muro J, et al. SEOM clinical guidelines for the treatment of renal cell carcinoma. ClinTranslOncol. 2014:16((12)): 1043-50.
5. Cheville JC, Lohse CM, Zincke H, et al. Sarcomatoid renal cell carcinoma: an examination of underlying histologic subtype and an analysis of associations with patient outcome. Am J SurgPathol. 2004;28(4):435-41.

6. Yan Y, Liu L, Zhou J, et al. Clinicopathologic characteristics and prognostic factors of sarcomatoid renal cell carcinoma. J Cancer Res ClinOncol. 2014;2.

7. Kavolius JP, Mastorakos DP, Pavlovich C, et al. Resection of metastatic renal cell carcinoma. J ClinOncol. 1998;16(6):2261-6.

8. Fang $X$, Gupta N, Shen SS, et al. Intraluminal polypoid metastasis of renal cell carcinoma in gallbladder mimicking gallbladder polyp. Arch Pathol Lab Med. 2010;134(7):1003-9. doi:10.1043/2009-0453-OA.1.

9. Piehler JM, Crichlow RW. Primary carcinoma of the gallbladder. Arch Surg. 1997;112(1):26-30.

10. Chung PH, Srinivasan R, Lineham WN, et al. Renal cell carcinoma with metastases to the gallbladder: four cases from the National Cancer Institute (NCI) and review of the literature. UrolOncol. 2012;30(4):476-81. doi:10.1016/ jurolonc.2010.04.010.

11. Andrén-Sandberg A. Diagnosis and management of gallbladder polyps. North American Journal of Medical Sciences 2012. N Am J Med Sci. 2012; 4(5):203-11. doi:10.4103/1947-2714.95897.

12. Furukawa H, Kosuge T, Shimada K, et al. Small polypoid lesions of the gallbladder: differential diagnosis and surgical indications by helical computed tomography. Arch Surg. 1998;133(7):735-9.

13. Sultania M, Pandey $D$, Sharma J, et al. Delayed isolated port-site metastasis of gallbladder cancer following laparoscopic cholecystectomy: report of two cases. J Gastrointest Cancer. 2014;45 Suppl 1:188-91. doi:10.1007/s12029-014-9622-y.

14. Blute ML, Thibault GP, Leibovich BC, et al. Multiple ipsilateral renal tumors discovered at planned nephron sparing surgery: importance of tumor histology and risk of metachronous recurrence. J Urol. 2003;170(3):760-3.

15. Motzer RJ, Bander NH, Nanus DM. Renal-cell carcinoma. N Engl J Med. 1996; 335(12):865-75.

16. Machado NO, Chopra P. Pancreatic metastasis from renal carcinoma managed by Whipple resection. A case report and literature review of metastatic pattern, surgical management and outcome. JOP. 2009;10(4):413-8.

17. GarcíaTabar PJ, Montoya Lirola MD, EtxepareArrosagaray P, et al. Spontaneous disappearance of pulmonary metastasis secondary to renal cell carcinoma after nephrectomy. Presentation of a case and review of the literature. ActasUrol Esp. 1997:16(5):430-4.

18. Chang KC, Chan KL, Lam CW. Spontaneous regression of renal cell carcinoma metastases. Hong Kong Med J. 1999:5(1):72-5.

Submit your next manuscript to BioMed Central and we will help you at every step:

- We accept pre-submission inquiries

- Our selector tool helps you to find the most relevant journal

- We provide round the clock customer support

- Convenient online submission

- Thorough peer review

- Inclusion in PubMed and all major indexing services

- Maximum visibility for your research

Submit your manuscript at www.biomedcentral.com/submit
Ciomed Central 